Background: HER2 consists of an extracellular domain (the target for trastuzumab), a transmembrane domain, and an intracellular domain, which is recognized by an antibody used in the immunohistochemical assessment of HER2 overexpression. The study consisted of $31 \mathrm{pa}-$ tients with metastatic breast cancer treated with trastuzumab.

The aim of the study was to evaluate retrospectively expression of extracellular and intracellular HER2 domains in primary breast cancers treated with surgery and to assess their correlation with biological features of tumours, disease-free survival, overall survival, as well as progression-free survival and survival since the start of trastuzumab treatment. Material and methods: All these patients relapsed and were treated with trastuzumab because of metastatic disease - none of them received trastuzumab in an adjuvant setting. Two kinds of antibodies were used in immunohistochemical evaluation: against extracellular and intracellular domains of the HER2.

Results: A significant correlation between different patterns of HER2 domain overexpression and disease-free survival was found. Disease-free survival (the time from the primary operation to relapse - prior to the start of any palliative treatment) was the shortest in patients with overexpression of both domains compared to patients without overexpression of both domains and the group with intracellular domain overexpression combined with absence of extracellular domain overexpression (median 13.2 vs. 24.3 vs. 52.4 months, $p=0.01$ ). There was no significant difference between these 3 groups of patients in aspects of biological features of tumours, overall survival, progression-free survival and survival since the start of trastuzumab treatment.

Conclusion: Concurrent assessment of extracellular and intracellular domains of HER2 may have prognostic value for HER2-positive patients.

Key words: extracellular domain, intracellular domain, HER2, trastuzumab.

\section{Prognostic value of expression of intracellular and extracellular domains of HER2 in patients with HER2-possitive breast cancer}

\author{
Sylwia Dębska, Renata Kusińska², Urszula Czernek', \\ Katarzyna Szydłowska-Pazera', Maria Błasińska-Morawiec ${ }^{3}$, \\ Izabela Dowgier-Witczak³, Elżbieta Olas ${ }^{3}$, Andrzej Kulig ${ }^{4}$, \\ Magdalena Jakubiak-Wielganowicz ${ }^{5}$, Piotr Potemski ${ }^{1}$ \\ 1Department of Oncology, Medical University of Lodz \\ 2Department of Pathology, Chair of Oncology, Medical University of Lodz \\ ${ }^{3}$ Mikolaj Kopernik Voivodeship Specialist Hospital, Lodz \\ ${ }^{4}$ Department of Clinical Pathomorphology, Polish Mother's Memorial Hospital \\ - Research Institute, Lodz \\ ${ }^{5}$ Department of Histopathology, MSWiA Hospital, Lodz
}

\section{Introduction}

$25 \%$ of breast cancer patients overexpress HER2 [1-5]. The extracellular domain of the receptor is present on the cancer cell surface and it is a target for the anti-HER2 antibody trastuzumab. Nowadays immunotherapy with trastuzumab presents a part of adjuvant and palliative treatment of patients with HER2-positive breast cancer. Adjuvant treatment with the antibody allows for $38 \%$ reduction of relative risk of recurrence and 34\% reduction of relative risk of death [6-10]. More than half of patients with metastatic breast cancer treated with trastuzumab-based regimens may achieve an objective response and they have longer progression-free survival and overall survival than patients treated with chemotherapy alone [11, 12]. Treatment with the antibody is slightly less effective as monotherapy - for this regimen the objective response rate is $19-26 \%[13,14]$.

HER2-positive breast cancer is regarded as an especially aggressive subtype of the disease. It is associated with early relapse and some poor prognostic factors such as lymph node involvement, hormone receptor (HR) negativity, higher mitotic index and higher grading $[2,4,5,15,16]$.

Only patients with HER2 overexpression are eligible for trastuzumab treatment. For this reason immunohistochemical assessment of the receptor expression in cancer cells in all newly diagnosed patients is obligatory. HercepTest is an immunohistochemical kit commonly used in Poland for HER2 testing. It includes rabbit anti-human HER2 protein which is specific for a fragment of the intracellular domain of the receptor. A dedicated scoring system is provided for the staining assessment - tumours with score 3+ are categorized as HER2-positive, 0 and 1+ tumours as HER2-negative. Tumours with intermediate score $2+$ need validation with fluorescent in situ hybridization (FISH), which detects HER2 gene amplification - only cases with an increased gene copy number are regarded as HER2 positive $[17,18]$.

HER2 is a 185 kDa phosphoprotein composed of 3 domains: extracellular, transmembrane and intracellular. The extracellular domain comprises a fragment recognized by trastuzumab. The intracellular domain has intrinsic tyrosine kinase activity $[19,20]$. There was identified a shorter variant of HER2 known as p95 receptor due to its molecular weight [21]. 

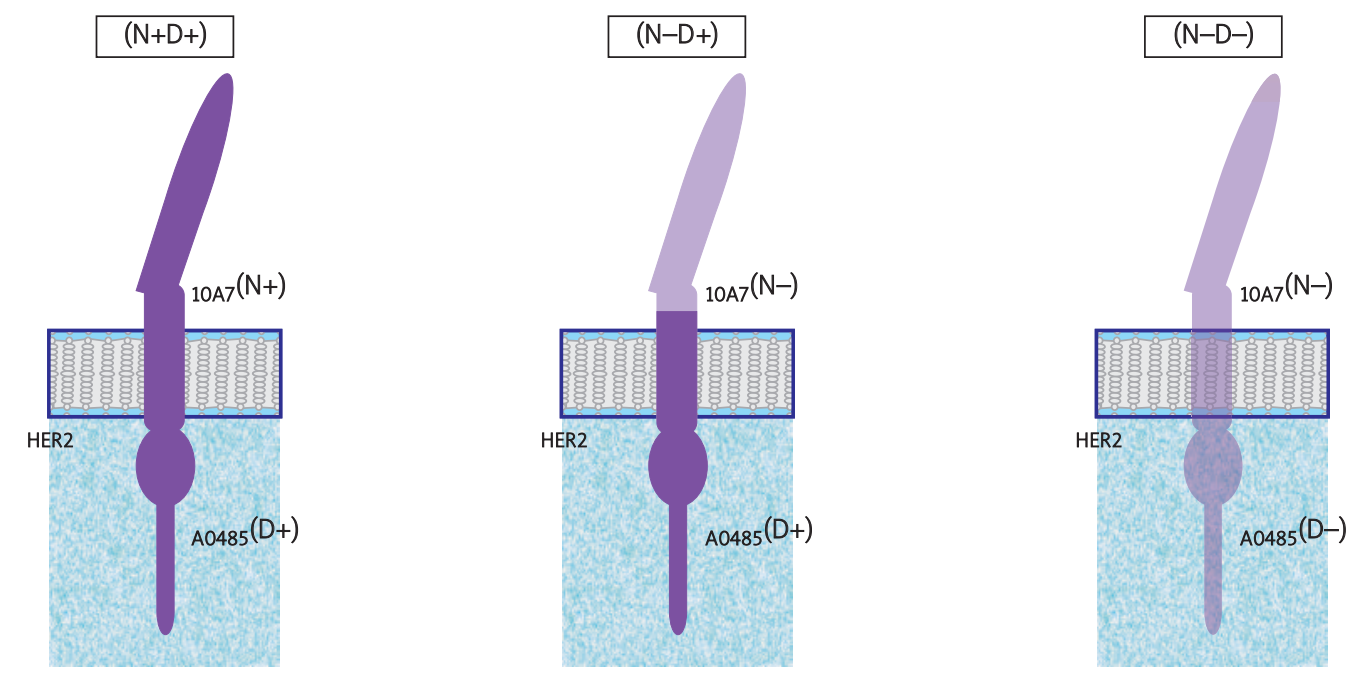

Fig. 1. Subgroups of patients dependent on coexpression of HER2 domains

\section{Aim of the study}

The aim of this study was to perform a retrospective analysis of extracellular and intracellular HER2 domains' expression in primary breast tumours of 31 patients treated with trastuzumab in a palliative regimen as well as assessment of its prognostic value and predictive value for immunotherapy.

\section{Material and methods}

Thirty one women with breast cancer treated with trastuzumab in 2003-2010 at the Oncology Department of Copernicus Memorial Hospital in Łódź, Poland were eligible for the study. All the patients were treated with trastuzumab in a palliative regimen with or without chemotherapy. All of them were primarily operated on and received adjuvant treatment without trastuzumab. The follow-up period from primary diagnosis to the date of death or the last observation varied between 19 and 139 months (median 62 mo.). Twenty-three patients were treated with trastuzumab combined with chemotherapy (CMF - 1, docetaxel -12 , etoposide -1 , paclitaxel plus carboplatin - 1, NF1 - 5, vinorelbine -3). Four patients were also treated with palliative ET. Twenty deaths were observed in this group.

Patients' primary breast tumours routinely fixed in formalin and embedded in paraffin were collected. They were immunohistochemically assayed for expression of extracellular and intracellular domains of HER2.

Polyclonal rabbit anti-human c-erbB-2 oncoprotein (A 0485, Dako) against intracellular domain and mouse monoclonal antibody RTU-CBE-356 (10A7, Novocastra) against extracellular domain were used in immunohistochemical analysis. Immunostaining was performed according to the manufacturer's instructions and it was visualized with Dako En Vision TM+ System. The expression of domains was identified by a pathologist with a light microscope and assessed according to the HercepTest scoring system. For both antibodies there was membrane staining in cancer cells. For the purpose of this study only tumours scored as $3+$ were re- garded as positive ones; tumours scored as 2+, 1+, 0 were regarded as lacking the domain expression. Depending on co-expression of domains, patients were categorized as belonging to one of three groups presented in Fig. 1.

Other collected data - hormonal receptor expression, grading, histological type, tumour size and nodal status - were included in routine histological reports made for the patients in the pathology departments of 3 hospitals in Łódź: Copernicus Memorial Hospital, Polish Mother Memorial Hospital and Department of Internal Affairs Hospital.

For 13 patients, due to preoperative systemic treatment, primary staging of disease was based on clinically evaluated characteristics such as tumour size and nodal status.

The association between co-expression of HER2 domains and various survival endpoints as well as objective response to immunotherapy were analysed. These survival endpoints included the following: disease-free survival (DFS), defined as the time from the primary operation to relapse (prior to the start of any palliative treatment); progressionfree survival (PFS), defined as the time from date of trastuzumab start to date of first progression or death; overall survival (OS), defined as the time from date of diagnosis to date of death or last observation; and overall survival from start of trastuzumab (OStrast), defined as the time from start of trastuzumab to date of death or last observation. Survival rates were estimated according to the Kaplan-Meier product limit method. Survival distributions were compared with the log-rank test.

Kruskal-Wallis analysis of variance and Fisher's exact test were used to verify correlations between the expression of both domains and biological and clinical features of the patients. Statistical significance was assumed when $p<0.005$. To analyse data and generate graphs StatsDirect (StatsDirect Ltd., England) and Statistica 9.1 (StatSoft Inc.) software were used.

\section{Results}

Patient clinical and histopathological characteristics are presented in Table 1. All patients had been treated with radical surgery before relapse occurred. Most of the patients had 
Table 1. Patient characteristics - stage of the disease, biological features of tumours, treatment

\begin{tabular}{|c|c|c|c|c|}
\hline Patient characteristics & $\begin{array}{c}\mathrm{N}+\mathrm{D}+ \\
(n=11)\end{array}$ & $\begin{array}{c}\mathrm{N}-\mathrm{D}+ \\
(n=10)\end{array}$ & $\begin{array}{c}\text { N-D- } \\
(n=10)\end{array}$ & $p$ \\
\hline Age at the moment of diagnosis - median & 51 & 53.5 & 48 & 0.357 \\
\hline Neoadjuvant chemotherapy & & & & 0.235 \\
\hline Yes & 6 & 5 & 4 & \\
\hline No & 5 & 5 & 6 & \\
\hline Mastectomy & 11 & 9 & 9 & 0.527 \\
\hline Breast conserving surgery & 0 & 1 & 1 & \\
\hline Adjuvant chemotherapy & & & & 0.645 \\
\hline Yes & 11 & 10 & 9 & \\
\hline No & 0 & 0 & 1 & \\
\hline Adjuvant hormone therapy & & & & 0.999 \\
\hline Yes & 4 & 4 & 3 & \\
\hline No & 7 & 6 & 7 & \\
\hline Adjuvant radiotherapy & & & & 0.732 \\
\hline Yes & 7 & 5 & 7 & \\
\hline No & 4 & 5 & 5 & \\
\hline T1-T2 & 6 & 7 & 6 & 0.897 \\
\hline T3-T4 & 5 & 3 & 4 & \\
\hline$N(-)$ & 2 & 4 & 1 & 0.323 \\
\hline$N(+)$ & 9 & 6 & 9 & \\
\hline G1-2 & 2 & 2 & 1 & 0.756 \\
\hline G3 & 5 & 4 & 7 & \\
\hline Gx & 4 & 4 & 2 & \\
\hline$E R / P R+$ & 3 & 3 & 3 & 0.999 \\
\hline $\mathrm{ER} / \mathrm{PR}-$ & 8 & 7 & 7 & \\
\hline TNM staging & & & & 0.521 \\
\hline I-II & 6 & 8 & 6 & \\
\hline III & 5 & 2 & 4 & \\
\hline Palliative trastuzumab started as & & & & 0.357 \\
\hline Monotherapy & 3 & 4 & 1 & \\
\hline Combined with chemotherapy & 8 & 6 & 9 & \\
\hline Number of lines of palliative regimens & & & & 0.172 \\
\hline $1-2$ & 8 & 5 & 3 & \\
\hline $3-5$ & 3 & 5 & 7 & \\
\hline Trastuzumab started as & & & & 0.156 \\
\hline $1^{\text {st }}$ line & 9 & 4 & 6 & \\
\hline $2^{\text {nd }}-5^{\text {th }}$ line & 2 & 6 & 4 & \\
\hline Trastuzumab beyond progression & & & & 0.732 \\
\hline Yes & 4 & 3 & 5 & \\
\hline No & 7 & 7 & 5 & \\
\hline Brain metastases & & & & 0.181 \\
\hline Yes & 1 & 4 & 4 & \\
\hline No & 10 & 6 & 6 & \\
\hline
\end{tabular}

ductal breast cancer. One patient was diagnosed with lobular cancer and one patient with apocrine cancer. For 9 patients treated with preoperative chemotherapy, tumour grading was not possible. In 19 patients metastatic disease was localized in bones, soft tissue or lymph nodes. In 12 patients recurrence was observed in lungs, liver or brain.

All patients were screened for HER2 overexpression with immunohistochemical HercepTest.
Twenty-eight patients were scored as HER2 3+. Three patients were scored as HER 2+ and these results were further validated with FISH. In 22 patients results of HercepTest were concordant with immunohistochemical staining with antibody against the internal domain (D), but only in 11 patients they were concordant with the staining against the external domain $(\mathrm{N})$.

The subgroup of patients with expression of both domains $(\mathrm{N}+\mathrm{D}+)$ had the shortest disease-free survival compared with 


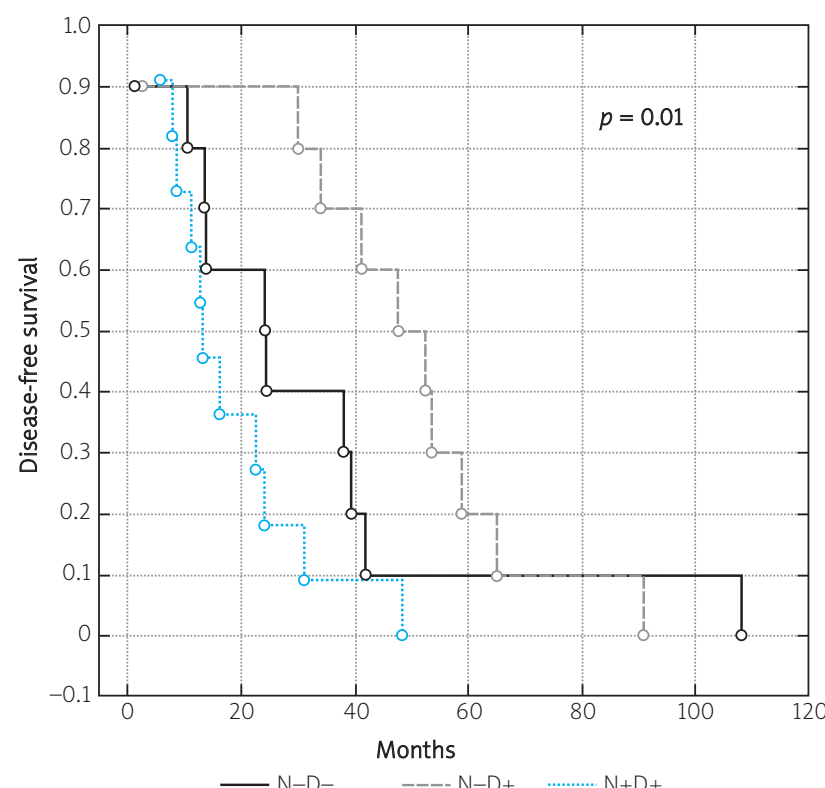

Fig. 2. Disease-free survival for patients with different expression of HER2 domains

the two other subgroups - the median DFS was 13.2 months in comparison with 24.3 and 52.4 months for N-D- and N-D+ subgroups respectively ( $p=0.01$ ) (Fig. 2). There was no association between the patterns of co-expression of domains and overall survival, progression-free survival or overall survival measured from the trastuzumab start date (Fig. 3).

In $\mathrm{N}-\mathrm{D}-$ and $\mathrm{N}-\mathrm{D}+$ subgroups there were more patients who developed brain metastases during anticancer treatment than in the $N+D+$ subgroup (4/10 vs. $4 / 10$ vs. $1 / 11$ ), but it was not statistically significant. There was also neither a connection between patterns of expression of domains and other clinical and biological features nor a predictive value of their expression for the response to trastuzumab-based therapy.

There were some differences in response to the treatment between patients who received the trastuzumab-based regimen as the first or subsequent lines of therapy, but they were not statistically significant. 12 of 31 patients achieved an objective response, but 9 of them received immunotherapy in the first line. PFS median values for patients who were treated with trastuzumab as the first or subsequent line were quite different (12.5 vs. 5.6 months, respectively), but not significantly. Patients in the "first line" group also had a tendency to live longer from the start of the immunotherapy than the patients in the "subsequent line" group (median 24 vs. 10.5 months, $p=0.057$ ).

\section{Discussion}

The majority of patients eligible for this study were diagnosed with ductal breast cancer; they had high grade tumours that lacked hormonal receptors and usually had lymph node metastases. These data are in agreement with other studies with HER2-positive breast cancer patients.

The results of the study indicate that the pattern of expression of HER2 domains may have additional prognos- tic value for patients with breast cancer. In patients who were primarily treated with breast surgery and adjuvant therapy without trastuzumab and then received the antibody due to recurrent, metastatic disease, different patterns of HER2 domains were associated with different disease-free survival. The patients with lack of external domain overexpression but with concurrent internal domain overexpression had the longest disease-free survival, while the patients with overexpression of both domains had the shortest. This is the first report concerning stratification of recurrence risk dependent on HER2 domains' co-overexpression in such a group of breast cancer patients.

However, only very specific patients were eligible for the study - patients who had the recurrence after radical surgery. Still there are no data about unselected patients with or without recurrent breast cancer, data that could be truly of prognostic value. The second important limitation of our study is the relatively small number of patients. It also should be mentioned that data from our study are not applicable to contemporary patients with operable HER2positive breast cancer, because they are treated with adjuvant trastuzumab, which reduces the risk of recurrence [22-24]. So it could be interesting to investigate the prognostic and predictive value of different patterns of expression HER2 domains in patients treated with adjuvant trastuzumab.

But still these data suggest that unidentified biological mechanisms may be responsible for the disease course in patients with different patterns of expression of HER2 domains, and exploration of this mechanisms could broaden our knowledge about breast cancer.

Some differences between immunostaining patterns in this study and results of the HercepTest may be caused by limitations of the immunohistochemical method. Apart from unquestionable advantages such as quick results, easiness and convenience of implementation, availability in most laboratories, low cost and application for paraffin-fixed tissue, it has some significant drawbacks. It is not a quantitative assessment and it can be affected by various factors such as subjective staining interpretation, the need for collaboration with an experienced pathologist, diverse sensitivity and specificity of antibodies, diverse protocols of method, long time of storage of paraffin-embedded tissue, and heterogeneity of examined tumours.

HercepTest was approved by the FDA in 1998 and became a commonly used method in clinical practice. But there are various anti-HER2 antibodies which have different sensitivity and specificity. Table 2 presents some studies in which they were used.

Some researchers suspect that differences between expression of internal and external domains of HER2 may be due to the receptor engagement in formation of heterodimers [26]. Other authors suggest p95 expression as an explanation of this phenomenon. Some data indicate that p95 originates from extracellular domain shedding of HER2. If the extracellular domain is cleaved by a metalloproteinase, the intracellular domain at the inner surface of a cell membrane should remain [31, 32]. According to other observations, p95 is generated by alternative translation, which is epigenetically regulated. It is possible thanks to internal ribosome entry sites 


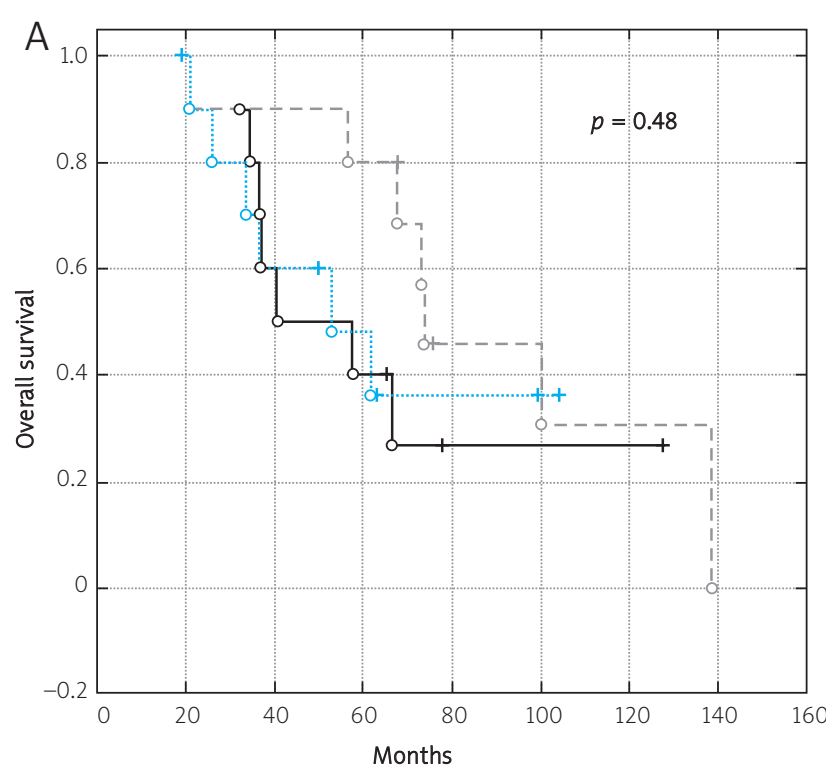

$-\mathrm{N}-\mathrm{D}-\quad$---- N-D+ $\ldots \ldots \ldots \ldots+\cdots+\mathrm{N}+$

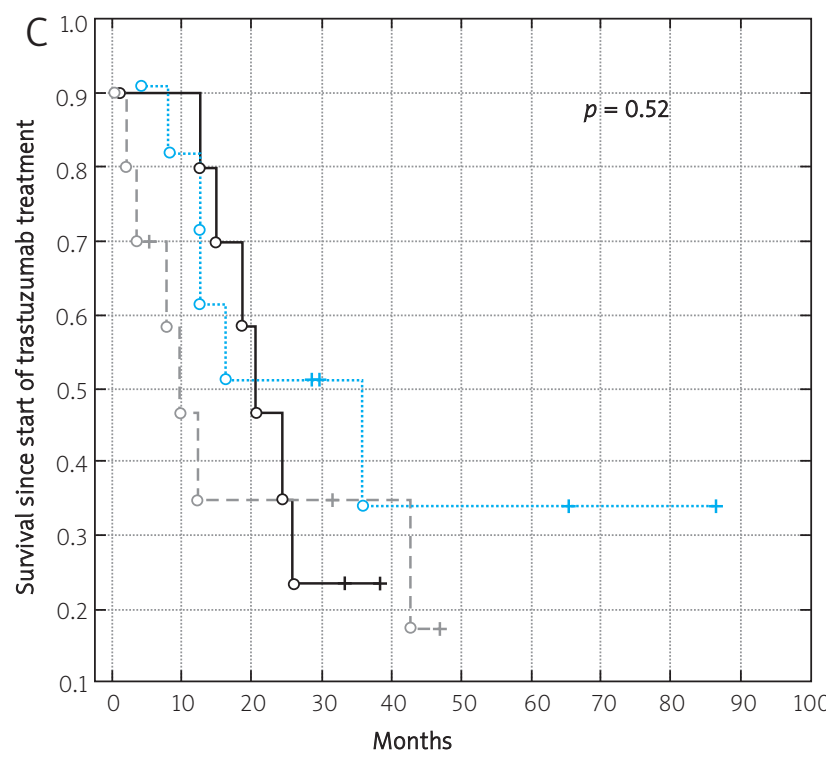

$-\mathrm{N}-\mathrm{D}-\quad---\mathrm{N}-\mathrm{D}+\quad \ldots \ldots \ldots . . . \mathrm{N}+\mathrm{D}+$

(IRES) present in the HER2 transcript as codons for methionine 611 and 687. These alternative protein products are also known as carboxyl-terminal fragments (CTF) [31-34].

P95 expression is regarded as a marker of poor prognosis and a negative predictive factor for trastuzumab treatment in patients with HER2-positive breast cancer [34]. Some studies have shown that 20-60\% of HER2-positive tumours express p95 [34-36]. This wide range of occurrence is an implication of various research methods such as Western blot [34-36], immunofluorescence [34] or immunohistochemistry [37]. According to Saez et al., patients with higher expression of p95 in cancer cells measured with Western blot had shorter disease-free survival than patients with lower expression (median 32 vs. 139 months, $p<0.0001$ ) [35]. P95 expression was associated with involvement of a higher num-

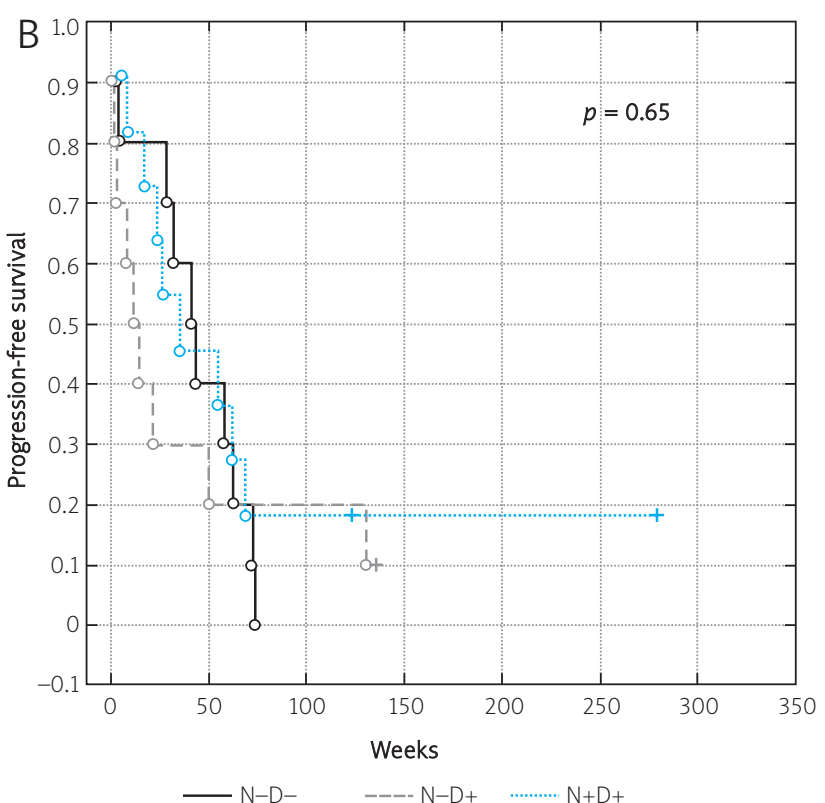

Fig. 3. A - Overall survival for patients with different expression of HER2 domains. B - Progression-free survival for patients with different expression of HER2 domains. C - Survival since start of trastuzumab treatment for patients with different expression of HER2 domains

ber of lymph nodes $(p=0.035)$, and oestrogen and progesterone receptor negativity $(p=0.013$ and $p=0.001$, respectively). In patients treated with a palliative regimen based on trastuzumab, expression of p95 was associated with shorter progression-free survival and overall survival. Scaltriti et al. used an immunohistochemical method and found p95 expression in 9 of 46 patients with metastatic breast cancer treated with trastuzumab. Only 1 p95-positive patient had an objective response to the treatment, while 19 of 37 p95negative patients responded to trastuzumab [34]. Similar patients were eligible for the Sperinde et al. study. They also found that patients with immunohistochemically detected expression of p95 had shorter progression-free survival (median 7.2 vs. 12.6 months, $p=0.007$ ) and overall survival (median 29 vs. 48 months, $p=0.012$ ). P95-positive patients also 
Table 2. Examples of studies evaluating HER2 expression with immunohistochemical tests using different antibodies

\begin{tabular}{|c|c|c|c|}
\hline Author & Anti-HER2 antibody & Study characteristics & Results \\
\hline $\begin{array}{l}\text { Ceccarelli } \\
\text { (1999) [26] }\end{array}$ & $\begin{array}{l}\text { anti-internal domain } \\
\text { antibody - clone CB11, } \\
\text { anti-external domain } \\
\text { antibodies - clones } \\
\text { CBE1 and Tab250 }\end{array}$ & $\begin{array}{l}\text { assessment of HER2 } \\
\text { expression in unselected } \\
\text { patients with breast cancer } \\
\text { and its association with other } \\
\text { biological features of primary } \\
\text { breast tumours }\end{array}$ & $\begin{array}{l}\text { Co-overexpression of both HER2 domains was found in } 26.5 \% \\
\text { of patients; internal domain overexpression without } \\
\text { external domain overexpression was present in } 10.8 \% \\
\text { of patients - they had involvement of axillary lymph nodes } \\
\text { more frequently and more lymph nodes were involved } \\
\text { in these patients }\end{array}$ \\
\hline $\begin{array}{l}\text { Ainsworth } \\
(2005) \text { [27] }\end{array}$ & $\begin{array}{l}\text { anti-external domain } \\
\text { antibody CBE356, } \\
\text { HerceptTest }{ }^{\circledR}\end{array}$ & $\begin{array}{l}\text { comparison of } \\
\text { immunohistochemically } \\
\text { assessed overexpression } \\
\text { of HER2 and its gene } \\
\text { amplification, assessment } \\
\text { of their prognostic value } \\
\text { in unselected patients with } \\
\text { breast cancer treated with } \\
\text { surgery }\end{array}$ & $\begin{array}{l}89 \% \text { of patients with HER } 2 \text { amplification (FISH) had } 2+ \\
\text { or } 3+\text { score with CBE356 antibody, but } 66 \% \text { of them had } 2+ \\
\text { or } 3+\text { score with HerceptTest; patients with } 2+\text { or } 3+\text { score } \\
\text { with CBE356 or HerceptTest }{ }^{\circledR} \text { had shorter overall survival }\end{array}$ \\
\hline $\begin{array}{l}\text { Bussolati } \\
(2005)[28] \\
\text { Sapino } \\
(2007)[29]\end{array}$ & $\begin{array}{l}\text { biotinylated } \\
\text { trastuzumab } \\
\text { (biotHER) }\end{array}$ & $\begin{array}{l}\text { assessment of HER2 } \\
\text { expression in patients with } \\
\text { breast cancer treated with } \\
\text { palliative trastuzumab }\end{array}$ & $\begin{array}{l}27 \text { of } 54 \text { patients had expression of HER2 external } \\
\text { domain (Busolati) } \\
47 \% \text { of patients had expression of HER2 external domain } \\
\text { (111 of } 234 \text { ) (Sapino) } \\
\text { in both studies expression of external domain was } \\
\text { associated with objective response to trastuzumab } \\
\text { treatment and reduction of risk of progression and death }\end{array}$ \\
\hline $\begin{array}{l}\text { Vinhas-Ricardo } \\
\text { (2007) [30] }\end{array}$ & $\begin{array}{l}\text { anti-external domain } \\
\text { antibody SP3, } \\
\text { anti-internal domain } \\
\text { antibody - clone CB11 }\end{array}$ & $\begin{array}{l}\text { assessment of HER2 } \\
\text { expression in unselected } \\
\text { patients with breast cancer } \\
(n=119)\end{array}$ & $\begin{array}{l}\text { internal domain overexpression was present in } 27 \text { patients } \\
(\text { CB11 3+), } 22 \text { of them also had external domain } \\
\text { overexpression (SP3 3+) }\end{array}$ \\
\hline
\end{tabular}

had metastases to lung ( $64 \%$ vs. $32 \%, p=0.015$ ), brain $(13 \%$ vs. $3 \%, p=0.11)$ and skin ( $29 \%$ vs. $16 \%, p=0.23)$ more frequently [37].

We assumed that expression of p95 could be detected by a specific antibody against its internal domain while the external domain was absent $-\mathrm{N}-\mathrm{D}+$ should be recognized as equivalent to $p 95$ expression. In that case this research would oppose the above quoted studies. N-D+ patients had the longest disease-free survival (pure prognostic value) and there was no association between patterns of the expression of domains and biological features or response to trastuzumab (no predictive value). But this is only an assumption as we did not directly assess p95. Thus, the comparison between presented results and results of other studies seems to be quite difficult. Of note, there is no standard method of assessment of p95 expression. Furthermore, in our study patients were dichotomized due to the presence or lack of domain overexpression. Another drawback which could influence these results is the use of different antibodies and different scoring systems in the studies. In our study, the scoring system of HercepTest was used for both antibodies to enable uniform assessment. A 0485 and RTU-CBE356 are examples of numerous anti-HER2 antibodies. Unfortunately their epitopes are unknown, while it is known that trastuzumab recognizes the fragment of extracellular domain near the cell membrane. It could be possible that RTU-CBE-356 (N) recognizes the epitope located above this point and there is a negative immunohistochemical reaction only when this fragment is lacking while the rest of the extracellular domain remains. That could explain why $N(-)$ patients responded to trastuzumab. Based on this assumption, it can be suggested that p95 may not be the only truncated form of HER2.

$\mathrm{N}-\mathrm{D}+$ patients who had longer DFS did not have prolonged overall survival. They had a similar response to trastuzumab as other groups, so this does not explain such inconsistency between DFS and OS. Of course, this may result from the small number of patients eligible for the study and very diverse approaches to palliative treatment. Heterogeneity of trastuzumab-based treatment could disguise supposed predictive value of coexpression of HER2 domains.

In summary, we have found that simultaneous assessment of internal and external HER2 domains may have additional prognostic value for patients with HER2-positive breast cancer. Patients with HER2-positive breast cancer not treated with adjuvant trastuzumab who are positive for both external and internal domains of HER2 had the shortest disease-free survival in comparison with patients with other patterns of expression of domains. Thus, different patterns of expression of HER2 domains may reflect different courses of disease. However, a study including patients treated with adjuvant trastuzumab is needed to validate the expected prognostic value of co-expression of HER2 domains.

\section{References}

1. Berger MS, Locher GW, Saurer S, Guilick WJ, Waterfield MD, Groner B, Hynes NE. Correlation of c-erbB-2 gene amplification and protein ex- 
pression in human breast carcinoma with nodal status and nuclear grading. Cancer Res 1988; 48: 1238-43.

2. Paik S, Hazan R, Fisher ER, et al. Pathologic findings from the National Surgical Adjuvant Breast and Bowel Project: Prognostic significance of erbB-2 protein overexpression in primary breast cancer. J Clin Oncol 1990; 8: 103-12

3. Gasparini G, Gullick WJ, Bevilacqua P, et al. Human breast cancer: prognostic significance of the c-erbB-2 oncoprotein compared with epidermal growth factor receptor, DNA ploidy, and conventional pathologic features. J Clin Oncol 1992; 10: 686-95.

4. McCann AH, Dervan PA, O'Regan M, Codd MB, Gullick WJ, Tobin BM, Carney DN. Prognostic significance of c-erbB-2 and estrogen receptor status in human breast cancer. Cancer Res 1991; 51: 3296-303.

5. Potemski P, Płuciennik E, Bednarek AK, et al. A comparative assessment of HER2 status in operable breast cancer by real-time RT-PCR and by immunohistochemistry. Med Sci Monit 2006; 12: MT57-61, 76.

6. Joensuu H, Bono P, Kataja V, et al. Fluorouracil, epirubicin, and cyclophosphamide with either docetaxel or vinorelbine, with or without trastuzumab, as adjuvant treatments of breast cancer: final results of the FinHer trial. J Clin Oncol 2009; 27: 5685-92.

7. Romond EH, Perez EA, Bryant J, et al. Trastuzumab plus adjuvant chemotherapy for operable HER2-positive breast cancer. N Engl J Med 2005; 353: 1673-84

8. Piccart-Gebhart MJ, Procter M, Leyland-Jones B, et al. Trastuzumab after adjuvant chemotherapy in HER2-positive breast cancer. N Eng J Med 2005; 353: 1659-72.

9. Dahabreh IJ, Linardou H, Siannis F, Fountzilas G, Murray S. Trastuzum ab in the adjuvant treatment of early-stage breast cancer: a sys tematic review and meta-analysis of randomized controlled trials. Oncologist 2008; 13: 620-30.

10. Viani GA, Afonso SL, Stefano EJ, De Fendi LI, Soares SV. Adjuvant trastuzumab in the treatment of Her-2-positive early breast cancer: a meta-analysis of published randomized trials. BMC Cancer 2007; 7: 153

11. Slamon DJ, Leyland-Jones B, Shak S, et al. Use of chemotherapy plus a monoclonal antibody against Her2 for metastatic breast cancer that overexpresses Her2. N Engl J Med 2001; 344: 783-92.

12. Marty M, Cognetti F, Maraninchi D, et al. Randomized phase II tri al of the efficacy and safety of trastuzumab combined with docetaxe in patients with human epidermal growth factor receptor 2-positive metastatic breast cancer administered as first-line treatment: The M77001 Study Group. J Clin Oncol 2005; 23: 4265-74.

13. Vogel CL, Cobleigh MA, Tripathy D, et al. Efficacy and safety of trastuzumab as a single agent in first-line treatment of HER2-overexpressing metastatic breast cancer. J Clin Oncol 2002; 20: 719-26.

14. Baselga J, Carbonell X, Castaneda-Soto NJ, et al. Phase II study of ef ficacy, safety, and pharmacokinetics of trastuzumab monotherapy administered on a 3-weekly schedule. J Clin Oncol 2005; 23: 2162-71.

15. Voduc KD, Cheang MC, Tyldesley S, Gelmon K, Nielsen TO, Kennec ke $\mathrm{H}$. Breast cancer subtypes and the risk of local and regional relapse. J Clin Oncol 2010; 28: 1684-91

16. Nguyen PL, Taghian AG, Katz MS, et al. Breast cancer subtype approximated by estrogen receptor, progesterone receptor, and HER-2 is associated with local and distant recurrence after breast-conserving therapy. J Clin Oncol 2008; 26: 2373-8.

17. Ellis IO, Dowsett M, Bartlett J, Walker R. Recommendations for HER2 testing in the UK. J Clin Pathol 2000; 53: 890-2.

18. Ross JS, Slodkowska EA, Symmans WF, Pusztai L, Ravdin PM, Hortobagyi GN. The HER-2 receptor and breast cancer: Ten years of targeted anti-HER-2 therapy and personalized medicine. Oncologis 2009; 14: 320-68

19. Waterman H, Sabanai I, Geiger B, Yarden Y. Alternative intracellu lar routing of ErbB receptors may determine signaling potency. J Biol Chem 1998; 22: 13819-27.

20. Brennan JP, Kumogai T, Berezov A, Murali R, Greene M. HER2/Neu: mechanisms of dimerization/oligomerization. Oncogene 2000; 9: 6093-101.

21. Molina MA, Codony-Servat J, Albanell J, Rojo R, Arribas J, Baselga J. Trastuzumab (Herceptin), a humanized anti-HER2 receptor monoclonal antibody, inhibits basal and activated HER2 ectodomain cleavage in breast cancer cells. Cancer Res 2001; 61: 4744-9.
22. Joensuu H, Bono P, Kataja V, et al. Fluorouracil, epirubicin, and cyclophosphamide with either docetaxel or vinorelbine, with or without trastuzumab, as adjuvant treatments of breast cancer: final results of the FinHer Trial. J Clin Oncol 2009; 27: 5685-92.

23. Romond EH, Perez EA, Bryant J, et al. Trastuzumab plus adjuvant chemotherapy for operable HER2-positive breast cancer. N Engl I Med 2005; 353: 1673-84.

24. Piccart-Gebhart MJ, Procter M, Leyland-Jones B, et al. Trastuzumab after adjuvant chemotherapy in HER2-positive breast cancer. N Engl J Med 2005; 353: 1659-72.

25. Rhodes A, Jasani B, Couturier J, et al. A formalin-fixed, paraffinprocessed cell line standard for quality control of immunohistochemical assay of HER-2/neu expression in breast cancer. Am J Clin Pathol 2002; 117: 81-9.

26. Ceccarelli C, Santini D, Gamberini M, et al. Immunohistochemical expression of internal and external ErbB-2 domains in invasive breast cancer. Breast Cancer Res Treat 1999; 58: 107-14.

27. Ainsworth R, Bartlett JM, Going JJ, et al. IHC for Her2 with CBE356 antibody is a more accurate predictor of Her2 gene amplification by FISH than HercepTestTM in breast carcinoma. J Clin Pathol 2005; 58: 1086-90.

28. Bussolati G, Montemurro F, Righi L, Donadio M, Aglietta M, Sapino A. A modified trastuzumab antibody for the immunohistochemical detection of HER-2 overexpression in breast cancer. Br J Cancer 2005; 92: 1261-7.

29. Sapino A, Montemurro F, Marchio C, et al. Patients with advanced stage breast carcinoma immunoreactive to biotinylated Herceptin are most likely to benefit from trastuzumab-based therapy: an hypothesis-generating study. Ann Oncol 2007; 18: 1963-8.

30. Vinhas-Ricardo SA, Milanezi F, Carvalho ST, Aguilera-Leitao DR, Lander Schmitt FC. HER2 evaluation using the novel rabbit monoclonal antibody SP3 and CISH in tissue microarrays of invasive breast carcinomas. J Clin Pathol 2007; 60: 1001-5.

31. Arribas J, Parra-Palau JL, Pedersen K. HER2 fragmentation and breast cancer stratification. Clin Cancer Res 2010; 16: 4071-3.

32. Anido J, Scaltriti M, Serra JJ, et al. Biosynthesis of tumorigenic HER2 C-terminal fragments by alternative initiation of translation. EMBO 2006; 5: 3234-44

33. Pedersen K, Angelini PD, Laos S, et al. A naturally occurring HER2 carboxy-terminal fragment promotes mammary tumor growth and metastasis. Mol Cel Bio 2009; 12: 3319-31.

34. Scaltriti M, Rojo F, Ocańa A, et al. Expression of p95HER2, a truncated form of the HER2 receptor, and response to anti-HER2 therapies in breast cancer. J Natl Cancer Inst 2007; 99: 628-38.

35. Saez R, Molina MA, Ramsey EE, et al. p95HER-2 predicts worse outcome in patients with HER-2-positive breast cancer. Clin Cancer Res 2006; 12: 424-31.

36. Molina MA, Saez R, Ramsey EE, et al. NH2-terminal truncated HER-2 protein but not full-length receptor is associated with nodal meta-stasis in human breast cancer. Clin Cancer Res 2002; 8: 347-53.

37. Sperinde J, Jin X, Banerjee J, et al. Ouantitation of p95HER2 in paraffin sections by using a p95-specific antibody and correlation with outcome in a cohort of trastuzumab-treated breast cancer patients. Clin Cancer Res 2010; 16: 4226-35.

38. Berger MS, Locher GW, Saurer S, Guilick WJ, Waterfield MD, Groner B, Hynes NE. Correlation of c-erbB-2 gene amplification and protein expression in human breast carcinoma with nodal status and nuclear grading. Cancer Res 1988; 48: 1238-43.

\section{Address for correspondence}

\section{Sylwia Dębska}

Department of Oncology

Medical University of Lodz

Pomorska 251

92-213 Łódź

e-mail: sylwia.debska@o2.pl 